\title{
A pattern of human dhole interaction in the buffer area of Jigme Khesar Strict Nature Reserve
}

\author{
Phub Dorji ${ }^{1}$ \\ ${ }^{1}$ Department of Forests and Park Services, Ministry of Agriculture and Forests
}

\begin{abstract}
Human-wildlife conflict is a serious problem for conservation efforts worldwide. This is also true for Bhutan, where carnivores depredate livestock of farmers, affecting farmer's livelihood, however, there is sparse documentation on the extent of human dhole interaction in Bhutan's some of the important areas of conservation interest. Therefore this research was aimed to evaluate the extent of human dhole interaction, income lost due to depredation, and the perception of the farmers towards dhole conservation. Data were collected from 160 households within two strata of the rural and semi-urban areas in western Bhutan through semi-structured questionnaires and focused group discussions. Livestock depredation involved seven predators, which caused the loss of $5 \%$ of the total average annual income of the farmers; which were significantly different between the predators involved. Dhole killed significantly more livestock than other predators and maximum kills were made in the rural area than semi-urban area. $60 \%$ of the incomes lost due to wild predators were caused by dhole with major impact in rural areas. The majority of the respondents from rural areas exhibited a negative attitude towards dhole conservation. They suggested livestock depredation compensation schemes and other livelihood alternatives minimize the impact of conflict, whereas the majority of the respondents from semi-urban suggested electric fencing around their village as measures to reduce human-wildlife conflict. Livestock compensation and insurance schemes, integrated conservation development programs, educational outreach programs with other livelihood alternatives such as ecotourism are recommended as intervention strategies to minimize human dhole conflict and create harmonic co-existence.
\end{abstract}

Keywords: Conflict, depredation, income, perception, rural, semi-urban.

\section{Introduction}

Human dhole interaction involves where the human encroach the dhole habitat and dhole come into the human-dominated periphery and cause threat or competition to the livelihood of the farmers. An increase in dhole population causes the livestock depredation, which results in a negative attitude of the farmers towards dhole, thereby killing the dhole in retaliation and impacting the dhole conservation (Tshering and Thinley, 2017). $72 \%$ of the respondents in the protected area of Thailand believe that increase in human dhole conflict was due to its habitat destruction by the alignment of roads (Jenks et al. 2014). Wang and Macdonald also stated that the influential factor contributing towards human dhole conflict includes increasing human population, loss of natural habitat, less pray and in some regions and increased dhole population resulted from conservation program actions (2006).

Bhutan is an agrarian country where the majority of the population are dependent on agriculture and livestock for their livelihood and most of the settlements are located in the proximity of the forest (Sangay and Vernes, 2008). The major wild predators depredating livestock includes tigers, common leopard, black bear, and dhole (Wang and Macdonald, 2006). Livestock depredations are common in areas where livestock holding forms the an integral part of farmer's livelihood ( Sangay and Vernes, 2014, Katel et al. 2014).

Among the wild predators, dhole caused a major negative impact on the livestock holding communities' livelihood (Dar et al. 2009, Sangay and Vernes, 2008). Human dhole interaction in form of livestock depredation has led to a threat to the dhole population by the farmers involved with the livestock rearing in its distribution ranges (Thinley et al. 2011). In Bhutan, dholes were nearly extirpated in the 1970s due to 
perceiving as pest to livestock and mass poisoning campaign for the dhole. Due to the increase in the population of wild pigs, the Bhutan government initiated reintroduction of dhole in the early nineties and now the species has re-established and its population is on the rise (Johnsingh et al. 2007).

Many incidences of livestock depredation by dhole were reported from rural and semi-urban areas in Bhutan (Wang and Macdonald 2006, Johnsingh et al. 2007, Thinley et al. 2011, Katel et al. 2014, Tshering and Phuntsho 2017). However, no information on the human dhole interaction is available from the buffer area of Jigme Khesar Strict Nature (JKSNR). This research was aimed to evaluate the extent of human dhole conflict, income lost due to depredation, and the perception of the farmers towards dhole conservation.

\section{Materials and Methods}

\subsection{Study area location}

This study was conducted in the buffer zone of JKSNR including part of four blocks, which lies between latitude $27^{\circ} 22^{\prime} \mathrm{N}$ to $27^{\circ} 1^{\prime} \mathrm{N}$ and longitude $89^{\circ} 1^{\prime} \mathrm{E}$ to $89^{\circ} 23^{\prime} \mathrm{E}$. It was located in western Bhutan covering 726.61 square kilometers $\left(\mathrm{km}^{2}\right)$ (Figure 1$)$.

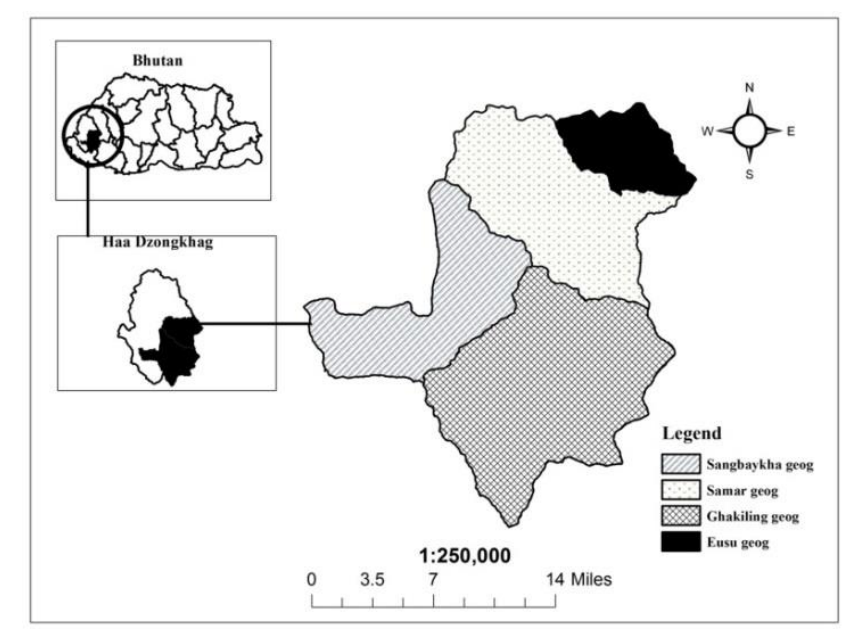

Figure 1: Study area location

\subsection{Sampling design}

Stratified random sampling was carried out (Wangyel, Lassoie, \& Curtis, 2006). The target population was households rearing livestock within the past five years because not all the households were rearing livestock (Alexander et al. 2015). From the target population, 50\% of the households from each village were randomly selected, which were treated as sampling units (Khan and Abbasi, 2015). Random selection of households was carried based on the random number generation against total households in the village using Microsoft excel. A total of 160 households were interviewed.

\subsection{Area stratification}

Four blocks were stratified into two strata based on the ecological zone, altitude, vegetation type, and proximity of the village to the urban zone. The principal criteria for the stratification of the survey area were the proximity of the settlements to the forest and national highway and town. Strata I was stratified as a rural area, as it is far away from the motor roads and there are no modern developmental activities taking place, whereas, strata II was stratified as semi-urban because the villages are within proximity to the national high way and all the villages are connected by motor road (Table 1).

Table 1: Study area stratification

\begin{tabular}{|l|l|l|l|l|l|}
\hline Strata & $\begin{array}{l}\text { Agro } \\
\text { ecological } \\
\text { zone }\end{array}$ & $\begin{array}{l}\text { Vegetation } \\
\text { type }\end{array}$ & Blocks & Category & $\begin{array}{l}\text { Elevation range (meter } \\
\text { above sea level (masl) }\end{array}$ \\
\hline Strata I & $\begin{array}{l}\text { Subtropical } \\
\text { zone }\end{array}$ & $\begin{array}{l}\text { Broad-leaved } \\
\text { forest }\end{array}$ & $\begin{array}{l}\text { Gakiling and } \\
\text { Sangbaykha }\end{array}$ & Rural area & $491-2,183$ \\
\hline
\end{tabular}




\begin{tabular}{|l|l|l|l|l|l|}
\hline Strata II & $\begin{array}{l}\text { Cool } \\
\text { temperate zone }\end{array}$ & Conifer forest & Samar and Eusu & $\begin{array}{l}\text { Semi-urban } \\
\text { area }\end{array}$ & $2,476-4,597$ \\
\hline
\end{tabular}

The idea behind stratification of the study area was to compare the significance, intensity, and prevalence of human dhole interaction in the different ecological zone and within the rural and semi-urban area with the hypothesis stating that the dhole population will be more with increasing distance from the national high way or in the rural area. This hypothesis was based on the assumption that the dholes avoid areas where there are high chances of human encounter and thus, will result in less livestock depredation (Borah, Deka, Dookia, \& Prasad Gupta, 2009).

\subsection{Data collection}

Data were collected using a semi-structured questionnaire (Jenks et al. 2014). Pre-testing of the questionnaire is pivotal in the enhancement of required and quality data collection (Woodroffe et al. 2005); therefore, pre-testing was carried out for six households, three each from two strata. Data collected during the pre-testing of the questionnaire were not included for analysis.

Interviews were carried out by visiting the household identified and respondents were interviewed separately to avoid the override information by the other respondent. The Head of the households was interviewed.

\subsection{Data analysis}

Stastical analysis of data was carried out using Statistical Package for Social Science (SPSS) Ver.23, ArcGIS 10.2, and Microsoft excel. Coding of the questions and the responses were done before analyzing the data. Both descriptive and inferential statistics were used for data analysis.

Data were tested for normality using a histogram with its normal curve and Kolmogorov normality test. Normal parametric data such as income from agriculture and income from livestock were analyzed using ANOVA to compare the income contribution between two strata.

Mann-Whitney U test was used to see the significant difference in mean annual income between two strata, average annual income from different income sources between two strata, mean annual income from livestock between two strata, mean livestock kill between two strata and mean income lost due to dhole in two strata.

Income lost due to livestock depredation by wild predators and dhole were non-parametric in nature, therefore Kruskal-Wallis and Mann-Whitney $U$ test were used to compare the difference within the predators and between the strata. A correlation was used to compare the relationship between the income and livestock lost to wild predators and dhole.

\section{Results and Discussions}

\subsection{Socio-economic characteristics}

Out of 160 respondents, $47.5 \%(n=76)$ were men and $52.5 \%(n=84)$ were women. Respondents from strata I comprises of $75.4 \%(n=44)$ male and $43.6 \%(n=34)$ female and strata II comprising of $40 \%(n=$ 32) male and 60\% $(n=50)$ female. The mean age of the respondents was $45.11 \pm 14.09$ with oldest respondent age of 82 and youngest of 19.

The average household member living at home was $(5 \pm 2.25)$ and household member's living at home in strata I $(4.910 \pm 2.07)$ was lower than in strata II $(5.22 \pm 2.15)$ with both the strata having a minimum of two and maximum of 12 members. The study conducted by Johnsingh et al., 2007 at Toebisa geog also found that the mean family members' size living in the semi-urban area (right bank) $(M=8.42)$ was higher than in the rural area $(M=5.78)$.

\subsection{Income source}

Residents are primarily subsistence farmers. Agriculture (61\%) and livestock (22\%) are the main sources of livelihood supplemented by non-farm activities. The non-farm activities include Non-Wood Forest product collection (3\%), remittance from the employee (3\%), business (6\%), and casual labor (4\%).

The average annual cash income of household from all sources including livestock was US\$ (1720.51 \pm 700.5) which was $91 \%$ higher than that of farmers in JSWNP (Wang and Macdonald, 2006) and 71\% higher than farmers in Toebisa geog (Katel et al. 2014) and the reason could be because in strata I farmers were growing cardamom as their main cash crop and in strata II farmers mean annual income was contributed by 
a combined force of agriculture, livestock, business, forest produce collection and casual labor, which provided better opportunities than farmers in Toebisa geog and JSWNP.

The average income of the respondents from strata I was US\$ (1808.46 \pm 647.94$)$ and strata II was US\$ (1845.26 \pm 750.67$)$. There was no significant difference in mean annual income per household between strata I and strata II $(U=3180, z=-.061, p>.05)$, because in strata I the average annual income from agriculture contributed $77.6 \%(15215.55 \pm 437.95)$ by the cultivation of cardamom as their main income source, whereas in strata II both agriculture $(841.72 \pm 427.13)$ and livestock $(526.58 \pm 616.24)$ contributed equally to the overall mean annual income per household followed by income from other non-farm activities. Katel et al. (2014) found that the average income of the farmer decreases as they move further away from the national highways and it contradicts the current finding because of the lucrative cardamom cultivation in a rural area in the current study site.

Average annual income from agriculture $(U=961.5, z=-7.64, p<.05)$, livestock $(U=1,801.5, z=$ $4.78, p<.05)$, forest produce collection $(U=1,340, z=-7.41, p<.05)$, business $(U=2,813, z=-2.52, p<.05)$, and casual labor $(U=2582.5, z=-3.27, p<.05)$ between two strata were significantly different, but it showed no significant difference in average annual income from employee support between two strata $(U=$ $3,088, z=-.67, p>.05)$. The average income from agriculture was US\$ (1116.08 \pm 515.23$)$, however, livestock contributed only US\$ $(399.78 \pm 577.94)$ towards the average annual income per household of the farmer. Therefore, in both, the strata income from agriculture contributed the maximum to the mean annual income. The result was consistent with the farmers in Arunachal Pradesh, where $66 \%$ of the household depends on subsistence agriculture (Lyngdoh, Gopi, Selvan, \& Habib, 2014). This is because farmers of these study sites shared similar economic zone.

The income of the farmers from agriculture was significantly high in strata $\mathrm{I}, H(1)=22.81, p<.05$, this was because the higher income from agriculture in strata I was highly contributed by cash from lucrative cardamom because of the agro-ecological zone. The sale of potato and vegetables were the main cash crop that contributed towards income from agriculture in strata II, which was minimal when compared to the cardamom.

Livestock contribution was only $14.73 \%$ towards farmer's livelihood in strata I and $28.5 \%$ in strata II (Table 2). The mean annual income from livestock between the two strata was significantly different, $U=$ $1,801.5, z=-4.776, p<.05$. This was because farmers in strata II has the easy excess to the market and in the semi-urban, there are demands for livestock product, whereas farmers in strata I keeping livestock mostly for their household consumption and not for income because there was no market for their livestock products. Non-farm activities contributed only $6 \%$ of the total average income in strata I and in strata II, it contributed $25.9 \%$, this was because in the semi-urban areas peoples were engaged in business, which alone contributed to $10 \%$ of the average annual cash income.

Table 2: Mean annual income contributors (\%)

\begin{tabular}{|c|c|c|c|c|}
\hline & \multicolumn{2}{|c|}{ Strata I } & \multicolumn{2}{c|}{ Strata II } \\
\hline $\begin{array}{c}\text { Income } \\
\text { contributor }\end{array}$ & Mean & $\%$ & Mean & \\
\hline Agriculture & $91,293.3 \pm 28467.4$ & 77.7 & $54,712 \pm 27763.4$ & 45.6 \\
\hline Livestock & $17,320.7 \pm 32830.5$ & 14.7 & $34,227.8 \pm 40055.9$ & 28.5 \\
\hline NTFP collection & $1,072.7 \pm 6074.7$ & 0.9 & $6,965.5 \pm 8636.6$ & 5.8 \\
\hline Employee support & $3,611.1 \pm 9479.3$ & 3.1 & $4,471.5 \pm 14705.3$ & 3.7 \\
\hline Business & $2,606.8 \pm 13209.9$ & 2.2 & $12,012.2 \pm 32981.5$ & 10 \\
\hline Casual labor & $1,645.3 \pm 6565.8$ & 1.4 & $7,552.9 \pm 15372.4$ & 6.3 \\
\hline
\end{tabular}

\subsection{Livestock holding}

Farmers in the study area were raising seven different types of livestock including cat and dog but yak had not raised in strata I because of its geographical location in lower elevation area. The cow was highest among other livestock types in both the strata (Strata I 37.4\%, $n=516$, Strata II 60\%, $n=834$ ) (Table 3). The mean annual livestock holding per household was $(17.29 \pm 17.97)$, including cat, dog, and poultry, which was $17.2 \%$ more than farmers in JSWNP Wang and Macdonald, 2006). This was because farmers in 
JSWNP were rearing the majority of the improved breed than in the current study site. Farmers in Kashmir were having a lower of $28.9 \%$ of livestock per household when compared with the current study site; it was because they never kept a wide variety of livestock, the majority were sheep and goats (Mir et al. 2015).

Both the strata were having similar numbers of livestock holding in the year 2016 (Strata I; $n=1,378$, Strata II; $n=1,389$ ). Farmers in the northern part of Nepal which were in proximity to the developmental zones holds $20 \%$ of livestock less than the farmers living further away from the urbanization, where, livestock and agriculture were the main means of rural livelihood sustenance (Thapa, 2015). The mean number of livestock holding per household in strata I was $(17.6 \pm 14.7)$ and in strata II was $(16.9 \pm 13.3 \%)$.

Table 3: Type of livestock holding of the respondents

\begin{tabular}{|c|c|c|}
\hline & Strata I & Strata II \\
\hline Livestock type & Total (\%) & $160(11.5)$ \\
\hline Yak & & $67(4.8)$ \\
\hline Horse & $90(6.5)$ & $834(60)$ \\
\hline Cow & $516(37.4)$ & $174(12.5)$ \\
\hline Ox & $238(17.3)$ & $31(0.1)$ \\
\hline Goat & $9(0.7)$ & $43(3.1)$ \\
\hline Poultry & $410(29.8)$ & $3(0.2)$ \\
\hline Cat & $55(4)$ & $76(5.5)$ \\
\hline Pig & $17(1.2)$ & $43(3.1)$ \\
\hline Dog & & \\
\hline
\end{tabular}

\subsection{Livestock holding characteristics and their protection measures}

Farmers in the study area were practicing four different types of livestock herding practices as stables or enclosures feeding, tethered in the field, send in the natural pasture or forest, and itinerant herding. Out of 160 households, more than half $58.1 \%,(n=93)$ send their cattle in the forest during daytime and $25 \%(n=$ 40) of households tether their livestock in an enclosure or field. The reason for those who send their livestock in the forest and never look after was because $57.1 \%(n=114)$ of households reported labor shortage as their problem for looking after the cattle, whereas in Toebisa geog, maximum (57\%) of the farmers never leave or keep their livestock in the forest. The difference in herding practices between the two study sites could be explained by the availability of labor to look after the cattle (Katel et al. 2014).

Relatively strata-wise livestock rearing mechanism showed that $76.9 \%(n=60)$ of households in strata I were sending their livestock in the natural pasture or forest during the daytime and never look after the livestock for a whole day. They were engaged only in sending their livestock to natural pasture or forest in the morning. In strata II, 40.2\% $(n=33)$ of households were engaged in sending their livestock in the natural forest during day time followed by $34.1 \%(n=28)$ tethering their livestock in their fields.

Stall feeding and keeping $(3.8 \%, n=3)$ in the enclosure was least practiced in strata I and even in strata II $(9.8 \%, n=8)$. Farmers in both the strata reported fodder shortage as one of the livestock rearing challenges and they could not stall-feed the livestock.

Respondents in strata I preferred compensation schemes with $46.2 \%(n=36)$ for livestock killed and in strata, II farmers would prefer electric fencing around the village with $41.5 \%(n=34)$ to reduce the impact of human dhole conflict. In Australia, ranchers were keeping livestock guarding dogs to prevent their livestock from depredation by a wild dog, where $65.7 \%$ of respondents asserted that depredation ceased after obtaining livestock guarding dogs (Van Bommel \& Johnson, 2012), so such measures can also be practical in Bhutan.

\subsection{Livestock depredation by dhole}

From the total of 233 livestock depredation by dhole, 54.2\% $(n=134)$ were cow followed by ox with $40.1 \%$ $(n=89)$, this result is consistent with Katel et al. (2014), who reported that local cattle kill by dhole was highest $89 \%,(n=141)$ in Toebisa geog. In JKSNR, livestock predation by dhole was maximum in strata I 
with $72.9 \%(n=170)$ kill while in strata II with $37.1 \%(n=63)$. The mean livestock lost to depredation by dhole in strata I was $(3.7 \pm .59)$ numbers per household per year and in strata II it was $(1.9 \pm .62)$. In both, the strata dhole depredation was highest among the other predators with maximum depredation on cow in both the strata (Strata I, 55.9\%, $(n=95)$, Strata, II $61.9 \%, n=39)$ and followed by ox (strata I $39.4 \%, n=$ 67, strata II $34.9, n=22$ ).

Seven types of livestock were lost to wild predators and dholes were responsible for four types of livestock such as cow, ox, horse, and yak. Livestock depredation by dhole comprises $52.6 \%(n=233)$ belonging to 88 households. This result conformed to the number of livestock killed by dhole with $34.7 \%(n=51)$ in Toebisa geog as the highest kill, as reported by Katel et al. (2014) and Tshering and Thinley (2017), also reported dhole to kill amongst the highest (49.9\%) but the result contradicts with Wang and Macdonald (2006) study in JSWNP, where leopard contributed 53\%, tigers $26 \%$ and dhole with $13 \%$ followed by bear $8 \%$. Thus, it is assumed that where there is the presence of top predators like tiger and leopard, dholes are less present. Dholes were also top predators in the neighboring regions like Arunachal Pradesh (70\%) (Lyngdoh, 2014) where there are no top predators like tiger.

\subsection{Age category of livestock kill and livestock depredation distance from the village}

From the total livestock kill by dhole, $55.8 \%(n=130)$ were adult $(>2$ years $)$ and $44.2 \%(n=103)$ were young ( $<3$ years). The kill age category of livestock by dhole showed no significant difference, $H$ (1) $=.2210, p>.05$, which indicates that dholes have no preferences over the age of the livestock for the kill.

The majority of dhole depredation was made within one $\mathrm{km}(52 \%, n=167)$ from the village (Figure 2), because the majority of farmers free-range their livestock in the nearer forest and never look after the cattle. They were engaged in sending in the morning and cattle come back to their shed in the evening, in which livestock become easy prey for the dhole within proximity to the village without attended (Johnsingh et al. 2007).

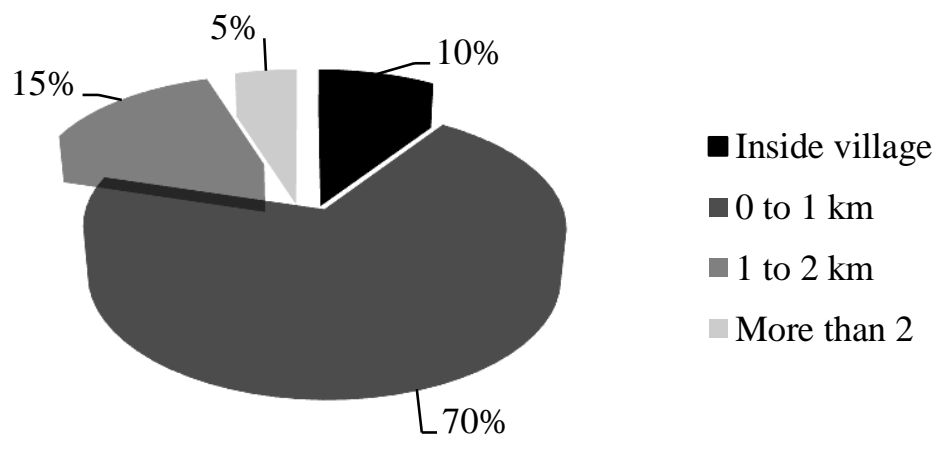

Figure 2: livestock kill distance of dhole from the village

\subsection{Farmer's income lost due to depredation by dhole}

From the overall income lost due to wild predators, dhole was responsible for $60 \%$ of the income loss. The average monetary value lost due to livestock predation by dhole for the last five years was US\$ 8872.6, which was 3\% of the total income holding during the last five years (US\$292371.12) of the respondents. The mean annual income lost due to dhole (60\%) was more in comparison with the mean annual income lost due to dhole (32.9\%) in Toebisa geog (Katel et al. 2014) and the mean annual income loss due to dhole $(13 \%)$ by the farmers in JSWNP (Wang and Macdonald, 2006). This was because in these two areas tiger also added to the livestock depredation, whereas no record of tiger kills was reported in the current study area.

The average value of livestock lost to dhole in strata I (US\$ 79.41) was much higher than in strata II (US\$ 32.65) (Figure 3) and in both the strata dhole contributed maximum to the income lost due to depredation (strata $\mathrm{I}=74.2 \%$, strata $\mathrm{I}=41.9 \%$ ). When we compared the income lost due to livestock depredation by dhole in two strata, dhole contributed $69.2 \%$ in strata I and only $30.2 \%$ in strata II, which was significantly higher in strata $\mathrm{I}(U=2,964.00, z=-.436, p<.05)$. 

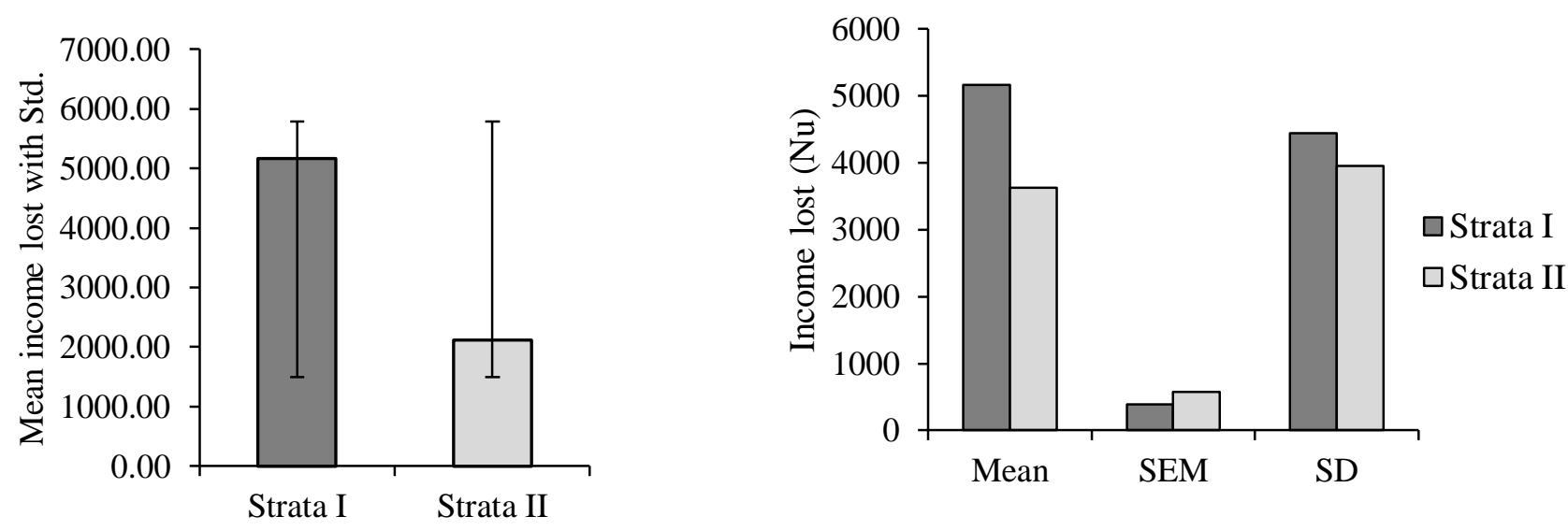

Figure 3: Mean income lost due to livestock depredation by dhole

\subsection{Farmer's attitude towards dhole conservation}

Out of 160 respondents, $99.3 \%(n=159)$ respondents knew dhole, where $90.6 \%(n=145)$ of the respondent have sighted dhole and 3.7\% $(n=6)$ have seen only in television. 38.1\% $(n=61)$ of respondent believes that the dhole population was increasing followed by $36.9 \%(n=59)$ with decreasing, $10 \%(n=16)$ believes that the population trend is not changing and 14\% $(n=24)$ of the respondents are not sure about the population trend of dhole.

The reason for the change in population trend as per respondent's opinion was that $17.5 \%(n=28)$ of the increase were due to reintroduction of dhole by the government in the 1970 s, followed by $8.8 \%(n=14)$ claiming for more breeding and no predator to kill dhole. $4 \%(n=4)$ of the respondents reported that habitat destruction and encroachment by a human were the cause for a decrease in dhole population and $5 \%(n=8)$ were not sure of the reason for population change.

Farmers have their different perception on the presence of dhole in their locality. The maximum number of respondents from both the strata (strata I, 48.7\%, $n=37$; Strata II, 52.4\% $n=43$ ) believed that present dholes were native to their locality, while $32.9 \%(n=25)$ from strata I and $17.1 \%(n=14)$ from strata II believes that both the native as well as introduced are present in their locality. $17.7 \%(n=28)$ respondents from the study site comprising $14.5 \%(n=11)$ from strata I and $20.7 \%(n=17)$ from strata II believe that the government had reintroduced dhole and reintroduced dholes are currently present in their locality (Table 4). This was supported by the statement made by Johnsingh et al. (2007) asserting that poisoning of dhole in the 1970s nearly extirpated the dhole existence and subsequently for last thirty years dhole problem was forgotten and absence of dhole bought enormous damage to crops by wild pig and dhole reappeared in most of Bhutan in late 1990s, which was assumed to be reintroduced and again started causing damage to livestock.

Table 4: Respondents perception on present dhole presence (\% in the parenthesis)

\begin{tabular}{|c|c|c|c|}
\hline & Strata 1 & Strata 2 & Total \\
\hline Native & $37(48.7)$ & $43(52.4)$ & $80(50.6)$ \\
\hline Introduced & $11(14.5)$ & $17(20.7)$ & $28(17.7)$ \\
\hline Both present & $25(32.9)$ & $14(17.1)$ & $39(24.7)$ \\
\hline No idea & $3(3.9)$ & $8(9.8)$ & $117)$ \\
\hline
\end{tabular}

\section{Conclusion}

Depredation by dhole not only made a significant impact on farmers' livelihood but also changed peoples' attitude towards dhole conservation effort. Livestock in the rural area is more vulnerable to dhole predation when they are free range in proximity to the villages. Dholes were the principal predator responsible for livestock depredation and causing a significant impact on farmer's livelihood. Cows were more vulnerable to dhole depredation in both strata because they are the most preferred livestock type in Bhutan. 
Dholes showed no preferences over the age category of the livestock for the kill. The attitude of the farmers towards the conservation of dhole is significantly associated with the degree of livestock loss, where the majority of farmers in rural are not in support of dhole conservation.

One of the reasons for not tethering the livestock on the farm was a shortage of fodder; this could be managed through providing fodder seeds and planting fodder trees in their unproductive agricultural lands. Initiating better alternative livelihoods such as improved agriculture and ecotourism initiatives can create a better livelihood in the village, where they don't have to depend on livestock for their livelihood. In the face of the fact that educational conservation projects can be used to mitigate human dhole clashes, literate farmers tend to be comparatively more conducive to conservation behavior. The reduction in the risk of destruction of livestock and the development of a harmonious dhole coexistence with farmers will contribute to one pillar of Bhutan's Gross National Happiness.

\section{Acknowledgement}

The authors would like to thank Gup, Tshogpa and the farmers of Eusu, Sama, Sangbaykha and Gakiling geogs for their cooperation and patience during data collection. Author would also would like to thank Mr. Sonam Dorji, Haa East Forest Management Unit Incharge, and Mr. Sherab Jamtsho, Haa range and Mr. Dechen Wangda and staff of Jigme Khesar Strict Nature for their support in field data collection. This work was supported by the Rufford Foundation under Grant number 18428-1.

\section{Reference}

[1] Alexander, J., Chen, P., Damerell, P., Youkui, W., Hughes, J., \& Riordan, P. (2015). Human wildlife conflict involving large carnivores in Qilianshan, China and minimal paw-print of snow leopards, Biological Conservation. 187(2): 1-9. doi:10.1016/j.bi.2015.04.002

[2] Borah, J., Deka, K., Dookia, S., \& Prasad Gupta, R. (2009). Food habits of dholes (Cuon alpinus) in Satpura Tiger Reserve, Madhya Pradesh, India, Mammalia. 73(2): 85-88. doi:10.1515/MAMM.2009.024

[3] Dar, N.I., Minhas, R.A., Zaman, Q., \& Linkie, M. (2009). Predicting the patterns, perceptions and causes of human-carnivore conflict in and around Machiara National Park, Pakistan, Biological Conservation. 142(10): 2076-2082.

[4] Jenks, K.E., Songsasen, N., Kanchanasaka, B., Leimgruber, P., \& Fuller, T.K. (2014). Local People's Attitudes and Perceptions of Dholes (Cuon Alpinus) around Protected Areas in Southeastern Thailand, Tropical Conservation Science. 7(4): 765-780.

[5] Johnsingh, A.J.T., Yonten, D., \& Wangchuk, S. (2007). Livestock-dhole conflict in western Bhutan, Journal of the Bombay Natural History Society. 104, 201-202.

[6] Katel, O.N., Pradhan, S., \& Schmidt-Vogt, D. (2014). A survey of livestock losses caused by Asiatic wild dogs, leopards and tigers, and of the impact of predation on the livelihood of farmers in Bhutan, Wildlife Research. 41(4), 300-310. doi:10.1071/WR14013

[7] Lyngdoh, S., Gopi, G.V., Selvan, K.M., \& Habib, B. (2014). Effect of interactions among ethnic communities, livestock and wild dogs (Cuon alpinus) in Arunachal Pradesh, India, European Journal of Wildlife Research. 60(5): 771-780. doi:10.1007/s10344-014-0846-8

[8] Mir, Z.R., Noor, A., Habib, B., \& Veeraswami, G.G. (2015). Attitudes of local people toward wildlife conservation: A case study from the Kashmir Valley, Mountain Research and Development. 35(4): 392-400. doi:10.1659/MRD-JOURNAL-D-15-00030.1

[9] Sangay, T., \& Vernes, K. (2008). Human-wildlife conflict in the Kingdom of Bhutan: Patterns of livestock predation by large mammalian carnivores, Biological Conservation. 141(5): 1272-1282. doi:10.1016/j.biocon.2008.02.027

[10] Sangay, T., \& Vernes, K. (2014). The economic cost of wild mammalian carnivores to farmers in the Himalayan Kingdom of Bhutan, Proceedings of the ecological society of Bhutan.1: 98-111.

[11] Thinley, P., Kamler, J.F., Wang, S.W., Lham, K., Stenkewitz, U., \& Macdonald, D. W. (2011). Seasonal diet of dholes (Cuon alpinus) in northwestern Bhutan, Mammalian Biology. 76(4): 518520. doi:10.1016/j.mambio.2011.02.003

[12] Tshering, K., \& Thinley, P. (2017). Assessing livestock herding practices of agro-pastoralists in western Bhutan: Livestock vulnerability to predation and implications for livestock management policy, Pastoralism. 7(1): 5. doi:10.1186/s13570-017-0077-1 
[13] Wang, S.W., \& Macdonald, D.W. (2006). Livestock predation by carnivores in Jigme Singye Wangchuck National Park, Bhutan, Biological Conservation. 129(4): 558-565. doi:10.1016/j.biocon.2005.11.024

[14] Wangyel, S., Lassoie, J.P., \& Curtis, P.D. (2006). Farmer attitudes towards conservation in Jigme Singye Wangchuck National Park, Bhutan, Environmental Conservation. 33(2): 148-156. doi: $10.1017 /$ S0376892906002931

[15] Woodroffe, R., Lindsey, P., Romanach, S., Stein, A., \& ole Ranah, S.M. (2005). Livestock predation by endangered African wild dogs (Lycaon pictus) in northern Kenya, Biological conservation. 124(2): 225-234. doi:10.1016/j.biocon.2005.01.028

[16] Van Bommel, L., \& Johnson, C. N. (2012). Good dog! Using livestock guardian dogs to protect livestock from predators in Australia's extensive grazing systems. Wildlife Research, 39(3), 220229. http://doi.org/10.1071/WR11135 